\title{
A Study of the Socioeconomic Impact of Mobile Phones on SMEs in the Waterloo Community, the Western Rural District of Sierra Leone
}

DOI: https://doi.org/10.47175/rissj.v2i2.211

\author{
| Hassan Elsan Mansaray | \\ Lecturer - Department of \\ Business Administration and \\ Entrepreneurship \\ Development, Institute of \\ Public Administration and \\ Management (IPAM) \\ University of Sierra Leone, \\ Freetown, Sierra Leone \\ hassanelsan@gmail.com
}

\begin{abstract}
To assess the impact of mobile phones on small and medium enterprises (SMEs) in the Waterloo Community, the researcher used qualitative research methods to do the study. It is selected with the intention of evaluating the socioeconomic impact on the use of mobile phones in the transport, Sand and stone mining as well as general merchandize/petty trading activities in the Waterloo community. Hence, simple random sampling technique was applied in selecting the number of participants that were involved in the study. The study discovered that the SMEs have contributed to socioeconomic development at certain level through the use of mobile phones. The impact of mobile phones in the Waterloo community involved: precise accounting and bookkeeping, making payments and collections, selling of products, and services to customers, connecting people, and increase business network opportunities and jobs creation.

The study further revealed the challenges faced by SMEs in their daily operations in the Waterloo community for example, increased competition from large firms, and multinational corporations, the ability to adjust to fast changing market demand, technological capacity, and change limitations linking knowledge, innovation, and creativity. Other challenges include lack of previous experience to run the SMEs, poor planning, no proper markets assessment, uncommercialized products, scanty marketing skills and lack of good corporate governance.

KEYWORDS

mobile phone; SMEs; socioeconomic; network; communication; community
\end{abstract}

\section{INTRODUCTION}

For over two decades the world has experience a colossal acceptance of mobile phones in developing countries. The tense growth of mobile phones in developing countries made the notion to use mobile phone network for more than voice and SMS message. Governments, Non-governmental organizations (NGOs), businesses are increasingly spinning their attention to the delivery of services through mobile phones in areas, such as economic development, health, education and human resource development. Past studies make known that mobile phones impact on the social and economic development, at least in two ways: i) by way of linking the poor, rural and disregarded areas to information that increase market opportunity; ii) through the delivery of a cost effective stage for governments to offer development activities such as, capacity development, education or private sector transformation (Samarajiva, 2011).

Furthermore, telecommunication or information communication technology has become the foremost actor in the business environment which has linked the world over. Ever since 
the introduction of mobile phones in Sierra Leone, business has become a little easier as compared to the former land line system and it has improved customer based philosophy. As mobile phone network increases in the country, the number of mobile phone users also increases simultaneously; business connectivity correspondingly increases. The latest concentration of how young entrepreneurs improve their businesses is the introduction of partnership support called small and medium enterprises.

In 2013, Sierra Leone economy was characterized as $70 \%$ of the informal sector contributing to the Gross Domestic Product (GDP) and the 30\% is from the formal sector involving mining and agricultural services. The national micro, small and medium enterprises program was developed through the solicitation of the International Finance Corporation (IFC) Group of the World Bank to see how the informal sector could be formalized and regulated. On 3rd, March, 2016, Sierra Leone parliament amended and passed into law the Small and Medium Enterprises Act to regulate and support entrepreneurs to support economic growth. In the Sierra Leone context, a small enterprise means an enterprise that has annual turnover of 100 million Leones and a medium enterprises is an enterprise that has annual turnover of more than 100 million Leones but does not exceed 500 million Leones yearly. The World Bank 2018 evaluating report on ease of doing business in Sierra Leone, discovered that the peaceful atmosphere in the country throughout the three consecutive peaceful elections and transfer of power from one political party to the other gave buoyancy to investors (Ministry of Trade and Industry 2013, World Bank 2018).

In addition, the use of mobile phones by Small and Medium Enterprises (SMEs) has contributed to the accomplishment of socioeconomic development towards the promotion of good governance, reduction of poverty, improvement of good health and education, building of human resource and empowerment universally. People are easily reached and issues of the day are communicated on mobile phones with a clear understanding of suspicion (Ahad 2016).

However, servicing mobile phone is not only limited to buying recharge cards, repairing the phones and constantly making sure that the device is always having constant power particularly in developing countries like Sierra Leone. The economic aggregate of mobile phone management is very high in developing countries, where electricity is a challenge and it only takes someone with courage to regularly use a mobile phone. One school of thought has it that if the servicing fee of a mobile phone is recorded, it might likely double the cost of medical service incurred a year, while another school of thought assumes that the cost benefit of using a mobile phone doubles the total expenditure of servicing a telephone the whole year. During the introduction of mobile phones in Sierra Leone, some people perceived mobile phone to be only for the rich and not for the poor. Sierra Leone has however benefitted from all the networks operating in the country despite challenges in the communication industry from the $2 \mathrm{G}$ system to the current $4 \mathrm{G}$ system (Statistics Sierra Leone 2016, CEMMATS Group Ltd 2018).

\section{LITERATURE REVIEW}

\section{General idea}

The Sierra Leone Ministry of Trade and Industry in 2016 registered 7,000 small and medium enterprises nationwide and re-verified them after the formation of Small and Medium Enterprises Development Agency (SMEDA) and have 1,110 operational in their data base on the going verification of small and medium enterprises. Sierra Leone entered the open market of mobile telecommunication system in 2001 instantly after the 10 years rebel war was confirmed over. This small country called Sierra Leone with an area of 144 
square miles has boundary with Guinea, Liberia and the Atlantic Ocean was in need of an opened market system and reasonable communications for people to reach the world. The year 2000 was the starting year of resilience and take-off for Sierra Leone and for Sierra Leoneans (Ministry of Trade and Industry 2016). Yet, small and medium enterprises in sub Saharan Africa and developing countries account for 2 to 3 employees for small enterprises while 3 to 5 employees' account for medium enterprises but provides the largest employment. In larger or richer economies above two third of employees are found in multinationals or larger enterprises. Besides, a smaller number work for micro enterprises, which suggests SMEs play a significant role in the economy (Snodgrass and Taylor 1996, Cull et. al. 2014).

Although some people believed that small and medium enterprises are playing a smaller role not significant as multinational enterprises in the economy yet, they control the greater part of the economy. SME'S are serious organisations that aid the development of any community and the state. In present day, the tense growth of mobile phone has been one of the most important occurrences throughout the world (Duncombe 2013). The introduction of Mobile Phones increases the existence of SMEs notwithstanding the risks and threats of technology. Furthermore, Mobile phones have many ways of communication which the Landline do not have but, it facilities have the positive and negative aspect. Before the coming of mobile phones, communication was very problematic, even for those using satellite phones. Voice calls and written messages were transmitted via fax machine. But today, communication is easier by using Voice calls, short messaging service or text messaging, internet, Facebook, WhatsApp as well as mobile banking known as mobile money (Cull et. al. 2014).

Since the introduction of the mobile system in Sierra Leone, up to the period 2007 to 2019 it is difficult to quantify the number of phone calls made in a second, minute and day because; proper statistics are not kept but it is estimated that about 50 calls are made in a second of a population of about 10,000 people either for business purposes or otherwise. The idea of mobile phone is essential because it geared towards connecting people. The use of mobile phones are increasing every day because people craved to connect with the world as well as have easier access on everyday activities (Londhe et al 2014, CEMMATS Group Ltd 2018).

\section{Voice Calls}

Mobile phone uses voice call system just like the landlines with thousands of calls throughout the world for businesses, official and other transactions. The development in technology from the first world has broadened the access and increases the use of mobile phones to poorer countries. Voice call is however an indication that someone calls and it shows the number or name of the caller if the caller is saved in your contact. This has helped the business community to be in contact with their customers at close or long distance. The merchants are one of the greatest beneficiary of voice calls from the inception of mobile phones in Sierra Leone so far. People engaged in business are currently finding it easier than it was before to reach their customers. With the introduction and use of mobile phones, there is connectivity among people and businesses especially for having knowledge of the market, making enquiries in terms of prices of goods and services and short falls. This is common in sub Saharan Africa countries (Aker and Mbiti, 2010, CEMMATS Group Ltd 2018, Das 2019). 


\section{Short Messaging Services (SMS) or Text Message}

The Short messaging Service is the use of mobile electronic device, typing and sending a short message to another user of a mobile electronic device in a simplest and cheapest form. Short messaging services (SMS) is a system that makes an holder of a mobile phone to reach another user of mobile phone in the simplest, cheapest and fastest means of communication. It is the fastest means of communication in the world that replaces fax messaging system to reach another person. The text messaging service is the fastest means of small and medium enterprises (SMEs) of Sierra Leone in reaching their customers easily at a cheaper and reasonable cost. A customer can make an order from his or her customer through text messaging or short messaging service. The request made can be responded to simply and instantly by showing what is available with quoted prices like it used to be when using the fax system of communication. Various research has proven that text message is a form of informal communication. Text messages are summaries of an intended transmission of short writing. Text messages are necessary for SMEs but have their gains and drawbacks in reaching out customers sometimes (Aker and Mbiti, 2010, Heitner, 2016)

\section{Internet}

The improvement in technology on mobile phones with internet facility has increased mobile phone use among business people. Before the introduction of mobile phones, people travelled distant places to get access to an internet café in search of relevant information. But today, (even in the village or remote area) with a smart mobile phone handset you are connected to the internet if, there is available network. This has widen SMEs connectedness across the globe. Internet can be accessed through Wi-Fi and another wider area network wireless system although not all SME'S are using the internet in transacting their businesses. It is very clear that the international business machine (IBM) profit has declined over the years and the production of computers has reduced. Internet cafe' businesses has dropped in many parts of the world and people only visited cafes if they had a document to be printed or scanned. As a result, many computer companies had to expand their product by fixing in some futures of computers to mobile phones (Chae and Kim 2003, Porteous, 2006 Jenkins, 2008, CEMMATS Group Ltd 2018, Amos-Abanyie 2019).

\section{Economic Impact on the Use of Mobile Phones}

Economic development is a process of economic transition involving the structural transformation of an economy through industrialization, rising GNP, and income per head. Economic growth on the other hand, contributes to the prosperity of the economy and is desirable because it enables the economy to consume and contribute to more goods and services by increasing investment, increase in labour force, efficient use of inputs to expand output, and technological progressiveness. Any nation that experiences economic development and growth will benefit from improvement in the living standards especially if the Government can assist in growth by implementing complementary and growthenhancing monetary and fiscal policies (Ackah and Vuvor 2011)

The SMEs are considered very important in many economies because they provide job, pay taxes, and are innovative as well as very instrumental in countries contributions in the global market. Beck and Kunt (2005) state that SME activity and economic growth are important because of the comparatively large share of the SME sector in most developing nations and the considerable international resources from sources like the World Bank group, that have been directed into the SME sector of these nations. Nevertheless, many 
researchers have perceived that SMEs improve competition and entrepreneurship so, they suggest that direct government support can boost economic growth and development. Equally, SMEs growth boost employment more than large firm because they are labour intensive and make better use of scarce resources with very small amount of capital. Hellberg (2000) also states that developing countries should be interested in SMEs because they account for large share of firms and development in these countries. Besides, SMEs are not only important because they are a source of employment but also because they are a source of efficiency, growth and economic decentralisation.

\section{Social Impact on the Use of Mobile Phones}

Communication plays a very significant role in the human life and telecommunications is a combined part of society. In the earlier days communication was very challenging due to the lack of appropriate means of communication which were very costly, unreliable and time consuming. Further, mobile phones can facilitate communication among social networks in response to shocks, thereby reducing households' exposure to risk. Because of all these reasons there was a great need of well-organized means of communication to save time and money and hard work. Therefore, with efficient use of telecommunication many restraints in any economic sector can be detached resulting in increased productivity and better administration (Aker and Mbiti 2010, MIT School of Technology 2011).

In Sierra Leone, the overall telecom market is approximately $\$ 200$ million per year, with data contributing to approximately $20 \%$ of the overall market. There are presently over 1 million data users engaging mostly in social networking in the country. The mobile phone market in Sierra Leone is dominated by two network providers: Orange SL Ltd, and Africell, a subsidiary of Lebanon-based Lintel Holding. And recently, Qcell SL Ltd being the third private network provider, but not with a wider network coverage like Orange and Africell. Orange SL Ltd is the leading telecommunications company in Sierra Leone, providing extensive coverage in the Sierra Leonean capital and other major towns and is set to expand mobile connectivity and internet access to customers living outside major urban areas. In the absence of the Company's operations in Sierra Leone, communications within the country would be bleakly limited, with far reaching impacts on various aspects of the Country's economy (Wittels and Maybanks 2016, CEMMATS Group Ltd 2018).

Mobile phones are popular among people for the applications they offer to users. Mobile phones make communications with people quite easier. People enjoy a lot of socioeconomic benefits in numerous forms of their daily work. Some rewards mobile phones offer are improved means of communication, learning choices to users, great exposure to the latest things, ways to personality development, modest ways to access applications, ideas to succeed in business, platforms to grow their applications and more. It is true that the mobile phones has a large impact on society and other aspects of life (Mobile 2017, Mobile 2019).

\section{Impacts of Mobile Phones on SMEs}

Existing literature gives a mention of different benefits that accumulate to mobile phone users, which include both businesses and individual users. Kakihara and Sorenson (2002) identified critical characteristics associated with the use of mobile phones to include interactivity, temporal, contextual and spatial mobility. These important features would not be available when using landlines. Barnes (2002) in contrast discerns that users of mobile phones do enjoy some ubiquity, flexibility and connectivity while Henfridsson and Lindgren (2003) complement that the users enjoy location awareness. According to Barnes (2002) these qualities facilitate the operations of organizations. Furthermore, the Barnes 
specifies that use of mobile phones improves the efficiency of production by business. They also help in the marketing and distribution of services and products of businesses in addition to the assistance they lend in the understanding of the markets by businesses as conversed by Hooper et al., (2010).

Moreover, the importance of mobile phones to SMEs is recognisable in the argument by Roldan and Wong (2008) who identifies three major importance. They specified that mobile phones act as tools for production, are used for information gathering and dissemination and can be used as tools for creating individual and business network opportunities. In explaining the assertions, they specify that mobile phones act as tools of production when they are used by the SMEs to transact business for instance by finishing an order or bidding for stock, which saves productive time for the enterprises. As a facilitator of information gathering and dissemination, they further argued that mobile phones helped in reducing the economic borderline in reaching out to customers and business partners. Supporting the argument for the use of mobile phone by businesses are Jensen (2007) and Rabayah and Qalalwi (2011) who discourse that mobile phones are helpful in realising better prices for services and therefore reducing the price fluctuations and dispersion.

Furthermore, the use of mobile phones confers five importance to both the consumers and producers as identified by Aker and Mbiti (2010). First, the authors argue that mobile phone usage leads to improvement in the access to and use of information, hence reducing the related costs including search costs. Second, the authors avow that mobile phone use improve the efficiency with which businesses do. Third, mobile phones helps in organizing different business partners and agents for SMEs therefore dropping the coordination costs. The fourth significance as recognized by the authors is that the mobile phone usage help in increasing the efficiency of markets hence reducing the costs resulting from market disorganization. Fifth, mobile phones ease communication among social networks as a result provide an effective response to shocks, therefore abridged exposure to risk. Aker and Mbiti (2010) have likewise noted that the acceptance and ensuing use of mobile phones by households has impacted positively in the transformation of their lives.

In spite of the irrefutable evidence of the existence of enormous importance of mobile phones usage to both households and the SMEs, there is still significant proportion of SMEs that are so far to take advantage of the opportunities offered through the enhanced information and communication technologies. Studies have indicated that there are a number of factors that have affected the use of mobile phones by businesses particularly the SMEs. For example, Mundim et al. (2000) recognized that the cost related with the use of the mobile phones as one of the reasons for the slowed adoption and use of mobile phones. Personal attributes of the mobile phone users was also stated in the study by Hooper et al., (2010) who also identified that the influence of others and the motivation of the user as other factors that influence the use of mobile phones. Hence, understanding the mobile phone usage from an enterprise perspective, the benefits supposed by an organization originate from the use of the mobile phones and the general organizational readiness, which are the major factors that influence the use of mobile phones by enterprises (Hooper et al, 2010).

\section{RESEARCH METHODS}

To appraise the socioeconomic impact of mobile phones on small and medium enterprises (SMEs) in the Waterloo Community, the researcher used qualitative research methods to carry out the study. As qualitative research is connected with observing attributes, behavioural patterns, features of participants experience with the purpose of analysing and 
interpreting the meaning of the human experience of the study. It embroils participant observation, semi-structured and unstructured interviews and retrospective account of the study (Flick 1998, Caruana et al 2014, Bhat 2019).

This study target population is 120 participants as the anticipated representative of the sample population. The sample size selection offers the researcher a full understanding of the participants' perspectives and knowledge about the selected SMEs at Waterloo community (Struwig \& Stead 2013, Burke \& Christensen 2014). In addition, the 5-point Likert scale was used for all closed-ended questions of the selected participants (Likert, 1932). In order to get the opinion of all participants from the selected SMEs, representatives were tracked from several units (cluster sampling) at the Waterloo community. 120 participants were selected to involve in the study: 40 from the Transport section, 40 from the Sand and stone mining business and 40 from the General Merchandize/Petty trading by using the simple random sampling technique and interviewed with closed-ended and open-ended questions. Data were also collected from secondary data.

\section{Research Environment}

Waterloo is a city in the Western Area of Sierra Leone and the capital of the Western area rural district. Waterloo is situated about twenty miles east of Freetown. The city had a population of 34,079 in the 2004 census and, an approximation of 40,000 in 2013.

Waterloo is a major urban transport centre and lies on the main highway connecting Freetown to the country's provinces. Waterloo is an wholly urban area, and lies about twenty five miles to Port Loko District entrance border line in the Northern Province (Map [N] All.com 2018, World Vision International 2019).

\section{RESULTS AND DISCUSSION}

The globe has seen a considerable acknowledgement of mobile phones in developing countries for over two decades now. The concerned growth of mobile phones in developing countries provoked the idea to use mobile phone network not just for voice and SMS communication but for business as well. Businesses are increasingly turning their attention to the delivery of services through mobile phones today. Also, ICT has become the leading player in the business ecosystem, which has connected the world over (Samarajiva, 2011). Since the introduction of mobile phones in Sierra Leone, business has become slightly easier as compared to the earlier land line system. Moreover, it has improved customer beliefs. Furthermore, the use of mobile phones by Small and Medium Enterprises (SME'S) has contributed in attaining the socioeconomic development in promoting good governance, reduce poverty, improved good health and education, building human resource and empowerment the world over and Waterloo Community is not an exemption (CEMMATS Group Ltd 2018)..

According to the study, (61)51\% of the respondents believed that SMEs have 'highly contributed' and (49)40\% 'fairly contributed' to the social development of the Waterloo community, whereas $6 \%$ said 'do not contribute to social development'. Similarly, (62)52\% and (50)41\% of the respondents believed that SMEs have 'highly' and 'fairly contributed' correspondingly to the economic development of the Waterloo community as well. While (5) $4 \%$ trust that said 'do not contribute to economic development'. This sensation about economic development had previously echoed by CEMMATS Group Ltd in their survey in 2018 that Mobile phones increase communication and improve companies' productive competence by allowing them to better manage their supply chains as well as create new jobs to address demand for mobile-related services, thereby 
providing income-generating opportunities in rural and urban areas (CEMMATS Group Ltd 2018).

Moreover, the use of mobile phone has made it easier and reasonable now to contact customers to meet their needs in probing for goods and services. Before the introduction of mobile phones, a number of business people had to travel distance to have access to vehicle to transport their goods. With the use of mobile phones, customers can find out areas they can buy goods and services they looked-for. This is obvious in this study when (48) $40 \%$ of the respondents believed that they 'sometimes' use mobile phone to chat or text, though (14)12\% said that they 'very often' use mobile phone to chat or text and; (34)28\% believed that they 'always' use mobile phone to chat or text, whilst (14)12\% said 'not often' and (5)4\% said 'never' use mobile phone to chat or text. Also, (63)53\%, (24) $20 \%$ and (30)25\% of the respondents respectively said that they 'sometimes', 'very often' and 'always' interact with customers through the use of mobile phone although, (1) $1 \%$ each believed 'not often' and 'never' interact with customers through the use of mobile phone. These confirm the purpose of people using mobile phones. Furthermore, mobile phones are the fastest means of small and medium enterprises at the Waterloo community in reaching their customers easily at a cheaper and reasonable cost. Besides, drivers as well can use mobile phones to make enquiries about areas they wanted to run their vehicles. This has increased the customer base and reduced risk and use of unnecessary fuel in hunt for goods.

Likewise, a customer can make an order from his or her customer through the mobile phone service. The request made can be replied to simply and directly by showing what is available with quoted prices. From the study (27)22\% of the respondents said 'sometimes' they use mobile phone to provide feedback to customers, (30)25\% said 'very often' and (26) $22 \%$ said 'always' provide feedback to customers, while (37)31\% did not respond to this question. Equally, customers can make appointments with other customers to deal with certain transactions without difficulty. As, (36)30\% of the respondents in this study trusted that 'sometimes' they use mobile phone to make appointments, (46)38\% said 'very often' and, (20)17\% held that they 'always' use mobile phone to make appointments whereas (5) $4 \%$ said 'not often' and (11)9\% supposed they 'never' use mobile phone to make appointments. Furthermore, (62)52\% of the respondents said they 'sometimes' and (36)30\% 'very often' use their mobile phones to contact, document and record their conversations with individuals or customers. While, (7)6\% said 'not often'. Also, (91)76\% said they 'sometimes', (17)13\% 'very often' (8)7\% 'always' use mobile phones for advertisement and marketing though (2) $2 \%$ 'not often and (1) $1 \%$ 'never' use mobile phones for advertisement and marketing.

Furthermore, the use mobile phone for accounting and book/keeping in the Waterloo community has become very useful and necessary for SMEs' accurate book keeping. For example, (87)72\% 'sometimes', (17)14\% 'very often' and (6)5\% said 'always' use mobile phones for accounting and book/keeping. Similarly, (92)77\% 'sometimes', (15)12\% 'very often' and (7)6\% 'always' use mobile phones to sell their products and services. Likewise (79) $66 \%$ of the respondents said they 'sometimes', (18)15\% 'very often' and (15)13\% 'not often' as well as (4)3\% 'never' use mobile phones for payments and collections. This recognized the awareness of the use of mobile phone as important because; it works towards connecting people and increase business network opportunities. The use of mobile phone importance was mentioned by Roldan and Wong (2008) in their study that mobile phones are used for information gathering and broadcasting and can be used as a tool for creating individual and business network opportunities. Analogous opinions were also reverberated by Aker and Mbiti (2010) that mobile phone usage leads to improvement in 
the access to and use of information, thereby reducing the related costs including search costs.

In similar way, mobile phone use has improved the efficiency with which businesses perform their production processes and supports in coordinating different business partners and agents for SMEs that have decreased the coordination costs. Furthermore, mobile phone helped in increasing the efficiency of markets henceforth reducing the costs resulting from market inefficiency. Additionally, mobile phones facilitate communication among social networks hence providing an effective response to shocks, hereafter shortened exposure to risk (Aker and Mbiti, 2010) .

Further, SMEs have contributed towards employment creation in the Waterloo community as was brought into existence in the study which, (50)42\% of the respondents held that SME's have contributed towards jobs' creation though; (45)37\% of the respondents presumed that SME's did not create enough employment, and (13)11\% said they only created employment for male. This assessment was reinforced by earlier research that revealed that the SME sector is considered very important in several economies because they make available jobs, pay taxes, are innovative and very instrumental in countries involvements in the global market. Likewise, SMEs growth boost employment more than large firms because they are labour intensive and make better use of scarce resources with very small amount of capital (Beck and Demirgiic-Kunt 2005).

Notwithstanding the benefits and drawbacks, SMEs also face challenges from increased competition, the ability to familiarise to fast changing market demand, technological change, and capacity constraints relating to knowledge, innovation, and creativity. For lots of SMEs, their potential is often not fully valued because of factors related to their small scale such as: lack of resources (finance, technology, skilled labour, market access, and market information). These challenges have been experienced in SMEs at Waterloo community. The study discovered that (49) $41 \%$ of the respondents believed 'sometimes', (16)13\% 'very often' and (48)40\% 'always' that SMEs lack finance owing to increase in competition.

\section{CONCLUSION}

However, most SMEs in the Waterloo community are launched by hopeful entrepreneurs who have had no previous experience, maybe even little exposure to a mature corporate environment. The enterprises are not planned properly, markets are not assessed, products not commercialized, marketing not adequate or imaginative, and good corporate governance frequently lacking. However, it is generally a crisis across Africa as a result of the nature of a tight labour market and few good opportunities for employment for the annual graduating students where they can watch and learn best practices. Also, Business Plan competitions inspire individuals, reasonably but unsuitably to get on their own projects. Yet, they have little access to financial products and services, little training in project management and preparation, and are ill-informed of basic business practices like viability studies. Poorer still, they are ignorant of the people, networks and support programs that do exist that could be of help (Anderson and Dunkelberg 1993, Willmett 2019).

Therefore, SMEs in the Waterloo community should confront the increased competition, the ability to adapt to rapidly changing market demand, technological change, and capacity constraints relating to knowledge, innovation, and creativity. If taken into consideration, it will help all the participants in the small and medium enterprise sector, (both the customers and producers (sellers) to take advantage of economies of scale and decrease their operating costs by adapting to cheaper and more efficient means of selling 
and buying. As well as accepting the use of mobile phones that may cover some in-built costs that the SMEs need to be aware of (Yoshino and Taghizadeh-Hesary 2016).

\section{REFERENCES}

Ackah J. and Vuvor S. (2011). Challenges faced by Small and Medium Enterprises (SMEs) - DIVA. Master's Thesis in Business Administration, MBA programme

Ahad M. T. (2016). Exploring the Usage of the Mobile Phones by SMEs in the Achievement of Vision 2020 Goals IBIMA Publishing Journal of Mobile Technologies, Knowledge, and Society http://www.ibimapublishing.com/journals/JMTKS/jmtks.html

Aker J.C. and Mbiti I. M. (2010) Mobile Phones and Economic Development in Africa Journal of Economic Perspectives -Volume 24, Number 3-summer 2010-Pages 207-232

Amos-Abanyie D. (2019). The impact of Mobile Money Services on Small and Medium Scale Enterprises (SME's) in Tema Municipality University of Ghana http://ugspace.ug.edu.gh

Anderson, R. L. and Dunkelberg J.S. (1993). Managing Small Businesses, West Publishing Company.

Barnes, S. J. (2002). Provision of services via the Wireless Application Protocol: A strategic perspective, Electronic Markets, 12(1), pp.14-21.

Beck T and Demirgiic-Kunt A. (2005). Small and Medium-Size Enterprises: Overcoming Growth Constraints. JEL Classification: L11; O1; O4

Bhat A. (2019). What is a Longitudinal Study?- Definition with Examples. Global VP Sales and Marketing at QuestionPro. https://www.questionpro.com/blog/longitudinalstudy/

Burke, J. \& Christensen, L. (2014). Educational research chapter 2: Quantative, qualitative, and mixed research. 5th Edition. London: SAGE Publications.

Caruana E.J., Roman M., Hermandez-Sanchez J., and Solli P. (2015). Longitudinal studies. Journal of Thoracic diseases. doi: 10.3978/j.issn.2072-1439.2015.10.63

CEMMATS Group Ltd. (2018). Environmental and Social Impact Assessment (ESIA) for Orange SL Ltd.'s Telecommunications Operations in Sierra Leone: Executive Summary and Main Report.

Chae, M. and Kim, J. (2003). What's so Different about the Mobile Internet? Communications of the ACM, 46, 12, 240-247.

Cull R, Davis L, Lamoreaux N and Roenthal J. L. (2014). Historical Financing of Smalland Medium Size Enterprises.

Das A. (2019). Impact of Mobile on Rural Life - An Emperical Study in Purba Medinipur, West Bengal A Journal of Composition Theory Volume XII Issue VIII August 2019 ISSN: 0731-6755

Duncombe R. (2013)b. Understanding Mobile Phone Impact on Lives in Developing Countries: A New Research Framework - Development Informatics Working Paper no.48.

Flick, U. (1998). An Introduction to Qualitative Research, London, Sage

Gustafsson J. (2017). Single case studies vs. multiple case studies: A comparative study https://www.semanticscholar.org/paper/Single-case-studies-vs.-multiple-case-studies

Hallberg, K. (2000). A Market Oriented Strategy for Small and Medium Enterprises, IFC Discussion Paper 40, p.5, Washington D.C.

Heitner D. (2016). Helping Kids Thrive (and Survive) in Their Digital World DO https://doi.org/10.4324/9781315213187 eBook ISBN9781315213187 
Henfridsson, O. and Lindgren, R. (2003). Facilitating in-car use of multi-context mobile services: the case of mobile telephone conversations, Americas Conference on Information Systems, Tampa, Florida.

Hooper, V., Kew, J. and Herrington, M. (2010). The use of mobile phones by SMEs in a developing economy: The case in South Africa, 18th European Conference on Information Systems, accessed at http.www. is2.lse.ac.uk/asp/aspecis/20100132.pdf, Jenkins B. (2008). "Developing Mobile Money Ecosystems," IFC and the Harvard Kennedy School, Washington DC, 2008.

Jensen R. (2007). The digital provide: Information (technology), market performance, and welfare in the South Indian fisheries sector, Quarterly Journal of Economics, 122 (3), pp.879-924.

Jensen, R. (2007). Information, Market Performance and the Well-Being of the Poor: Evidence from South Indian Fisheries', Harvard University (working paper).

Kakihara, M. and Sorensen, C. (2002). Mobility: An Extended Perspective, 35th Hawaii International Conference on System Sciences, Maui, Hawaii.

Likert R. (1932). A Technique for the Measurement of Attitudes https://legacy.voteview.com/pdf/Likert_1932.pdf

Londhe, B. R., Radhakrishnan, S., \& Divekar, B. R. (2014). Socio Economic Impact of Mobile Phones on the Bottom of Pyramid Population - A Pilot Study. Procedia Economics and Finance, 11(14), 620-625. https://doi.org/10.1016/s22125671(14)00227-5

Map [N] All.com (2018) Waterloo, Sierra Leone. http://174.127.109.64/en/MapWaterloo_1135522.html

Ministry of Trade and Industry (2013) Agribusiness Partners http://www.maf.gov.sl/MTI.html

MIT School of Technology (2011). Importance of Telecom in Various Sectors. http://www.mitsot.com/blog/importance-of-telecom-in-various-sectors.html/

Mobile. (2019). Mobile Connectivity in Emerging Economies https://www.pewresearch.org/internet/2019/03/07/

Mobile. (2017). Impact of Smartphones over Society https://www.keyideasinfotech.com/blog/impact-of-smartphone-on-society/

Mundim A., Alessandro R. and Stocshetti A. (2000) SMEs in Global Market: Challenges, Opportunities and Threats, Brazilian Electronic Journal of Economics.

Porteous D. (2006). The Enabling Environment for Mobile Banking in Africa https://www.researchgate.net/publication/248515675

Rabayah, K.S. and Qalalwi, K. (2011). The Impact of Mobile Telephony On Developing Country Enterprises: A Palestinian Case Study, The Electronic Journal on Information Systems in Developing Countries, 46(4), 1-20.

Roldan, G. and Wong, A. (2008). Building micro-enterprises through information and Communication Technologies (ICT) in Bangladesh.

Samarajiva, R. (2011). "Mobile at the Bottom of the Pyramid: Informing Policy from the Demand Side," Information Technologies \& International Development, 7(3).

Snodgrass, D. R., and Taylor B. (1996). Industrialization and the Small Firm: Patterns and Policies. San Francisco: ICS Press.

Statistics Sierra Leone. (2016). Population and Housing Census summary of final results planning a better future Copyright (C) 2016

Struwig F. W. and Stead G. B. (2013). Research: planning, designing and reporting. 2nd edition. Cape Town: Pearson. 
Willmett S. (2019). 7 biggest challenges SMEs face - and how to overcome them. https://smallbusiness.co.uk/7-biggest-challenges-smes-face-and-how-to-overcomethem-2548160/

Wittels A. and Maybanks N. (2016). Communication in Sierra Leone: An Analysis of Media and Mobile Audiences. BBC Media Action.

World Bank. (2018). THE WORLD BANK ANNUAL REPORT 2018 www.worldbank.org/mfd

Yoshino N. and Taghizadeh-Hesary F. (2016). Major Challenges Facing Small and Medium-sized Enterprises in Asia and Solutions for Mitigating Them. ADBI Working Paper Series. 